\title{
Utilizing Science Outreach to Foster Professional Skills Development in University Students
}

\author{
Edward Eng \& Catherine Febria \\ University of Toronto Scarborough
}

Students seek unique experiences to obtain and enhance professional development skills and to prepare for future careers. Through the Let's Talk Science Partnership Program (LTSPP), a voluntary science outreach program at University of Toronto Scarborough, students are given the opportunity to continually improve on skills which include: the "3 Cs" (creativity, communication, cooperation), and leadership and organization skills through hands-on activities in classrooms and community centres across the city and in isolated rural communities. Volunteers serve as mentors, and frequently transfer knowledge related to their research and coursework to youth. Here, we present results from surveys on current and past volunteers (2004-2010). Volunteers were asked to evaluate the value of the skills they obtained through science outreach, and the relevance of those skills to obtaining current work and achieving long-term career goals. Respondents commented on the effectiveness of the skills they obtained and ranked the transferable skills. We show that volunteer work through LTSPP largely improves their communication and confidence skills. As well, students identified clear links between science outreach and professional goals, and highly recommended LTSPP to others.

\section{Introduction}

Science outreach is one way for university students $S_{\text {to }}$ develop transferable skills that are necessary for any future career. Students are encouraged to participate in extra-curricular activities to enhance their academic experience and activities such as science outreach and communication can also improve learning and comprehension. Universities, like the
University of Toronto Scarborough (UTSC), have also recognized the importance of providing students with a sense of responsibility to their community and have committed to enhancing the student experience to include more than just academics, but also service, leadership, and communication (Dolan, 2009). At the UTSC, few outlets existed 
for students to enhance their student experience or to develop other skills outside of their research and academic programs. The UTSC's Let's Talk Science Partnership Program (LTSPP) represents one of the few opportunities for students to learn, develop skills, and grow outside of their required studies. In this work, we sought to understand the impacts of volunteer science outreach experiences on past and current volunteers of the program.

\section{Let's Talk Science Partnership Program (LTSPP)}

Let's Talk Science is a national charitable organization that seeks to develop and deliver engaging science, engineering, and technology education to children and youth through hands-on, interactive programming. The Let's Talk Science Partnership Program is based out of Canadian universities. Coordinators partner university students with educators and students in the community to do hands-on science activities with children and youth in schools, libraries, and public community events. Incoming volunteers to the program receive Science with Impact ${ }^{\mathrm{TM}}$ training before conducting activities. The UTSC site was initiated in 2004, and began with one coordinator and five volunteers. Due to ongoing support from the community and University administrators, the program has now expanded to three coordinators and over 100 volunteers. Volunteers in the program at UTSC range from first-year undergraduates to senior graduate students, and come from various academic disciplines (science and non-science related). This provides a unique platform that enables the sharing of knowledge and expertise across disciplines, as well as interactions between junior and senior volunteers of the program. Currently, on average, volunteers participate in about 3-4 science events, reaching over 2000 students, per year.

\section{Data Collection and Analyses}

To assess the opinions of LTSPP volunteers, three different surveys were distributed to volunteers at different stages of volunteering: students who were beginning volunteer training; students who had completed at least one year of volunteer activities with LTSPP; and experienced undergraduate and graduate students who volunteered with LTSPP between 2004 and 2009. A sample of the survey can be found in the Appendix. A total of 34 surveys were collected and analyzed. Overall, respondents ranked their perceptions of the skills they obtained through volunteering and commented on the quality of their volunteer experiences. The skill categories examined in the study can be found in the Appendix. The ranking on how much each skill category was enhanced was based on the following Improvement Score scale: 1 - not at all; 2 - very little; 3 - somewhat; 4 - quite significantly; and 5 - very significantly. All responses were tallied and analyzed using Microsoft Excel software. A statistical t-test was used for analyses of the data for each skill category when comparing between undergraduate and graduate volunteers, active and non-active volunteers, and novice and experienced volunteers.

\section{Results}

\section{Distribution of skill enhancement of Let's Talk Science Partnership Program volunteers at UTSC}

Of the survey respondents, 14 were graduate students and 20 were undergraduate students. Ten respondents were alumni members and 24 were current active volunteers. The respondents conducted an average of five events per year. Taking all of the volunteers into consideration, of the 14 skill categories studied, the volunteers found their communication, presentation, interaction/engagement, and mentorship skills were most enhanced, whereas their reading/writing skills were least enhanced (Figure 1).

\section{Comparison of skill enhancement between undergraduate and graduate volunteers, and active and non-active (alumni) volunteers}

It is of interest to investigate whether particular groups of volunteers would find similar or different 


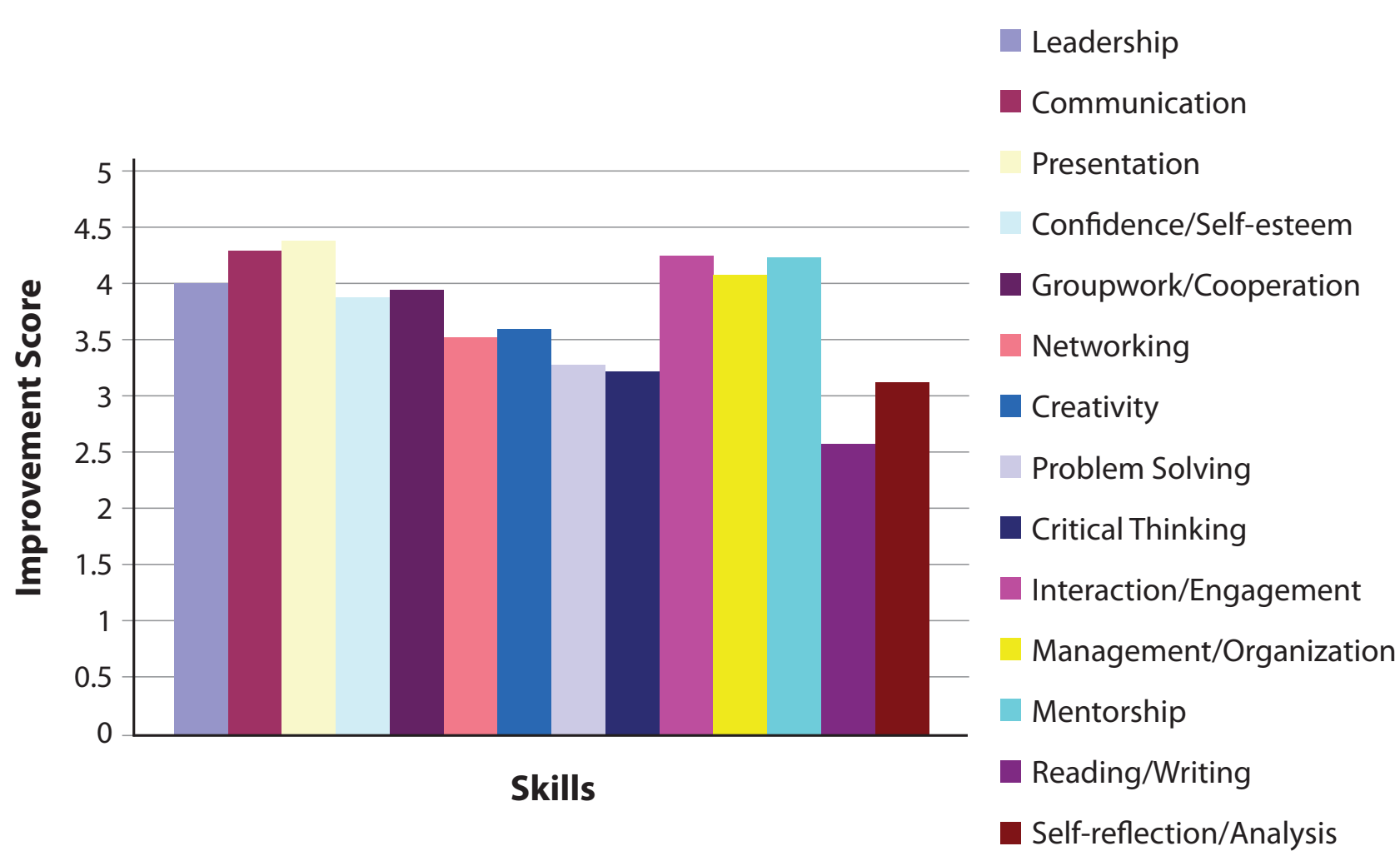

FIGURE 1

Distribution of Skill Enhancement of LTSPP Volunteers

skill sets being enhanced when comparing volunteers at different education or career levels. When comparing undergraduate and graduate students for each skill category, no significant difference was found. However, when looking at the general trend based on the improvement scores, graduate students ranked having enhanced mentorship and presentation skills through LTSPP. On the other hand, undergraduate students enhanced mainly their communication, presentation, and interaction skills through volunteering (Figure 2A). When comparing between alumni and active volunteers, creativity skills was found to be significantly more enhanced in alumni compared to active volunteers $(\mathrm{p}<0.05)$. Also, with respect to the improvement scores, alumni found that they benefitted most from improved mentorship, presentation, and organizational skills for their careers, and active volunteers benefitted most from improved communication and presentation skills (Figure 2B). The skills that were least enhanced by LTSPP included reading/writing, problem solving and critical thinking skills (Figures 2A and 2B).

\section{Comparison of skill enhancement between experienced and novice volunteers}

In addition to differentiating the impact of skill enhancement of the volunteers based on their education/career level, the amount of participation (which includes number of years and number of events) in the LTSPP program should be examined as well. This would determine which specific skill sets are enhanced at various stages within the program. When comparing volunteers that have been in the LTSPP program for more years to volunteers that were in the first year of the program, those with more years of experience found mentorship skills to be significantly enhanced compared to those with less than one year of experience $(\mathrm{p}<0.05)$ (Figure 3A). On the other hand, no significant difference was observed for each 


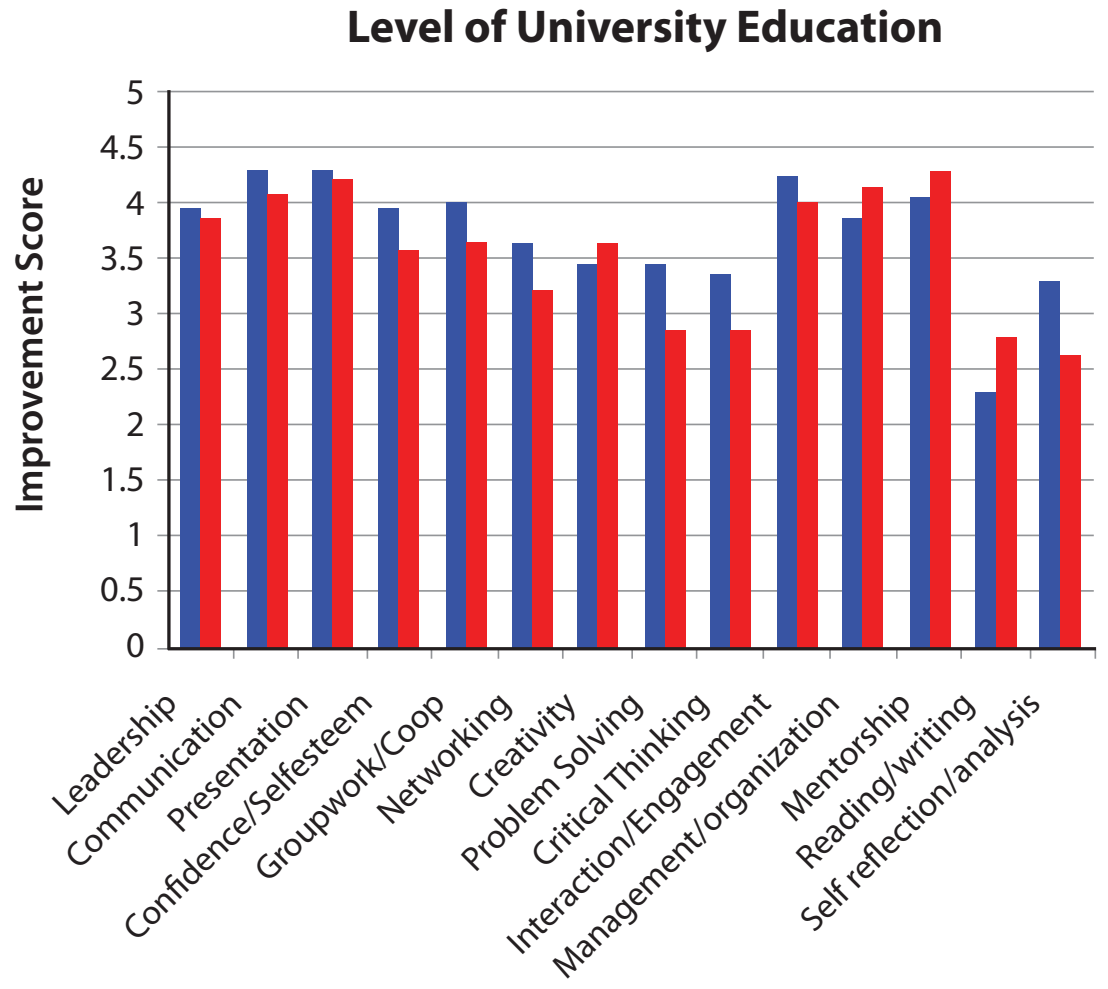

- Undergraduate

- Graduate

Figure 2A

Comparison of Skill

Enhancement Between

Undergraduate and Graduate

Volunteers in LTSPP

Skills

\section{LTSPP Volunteer Status}

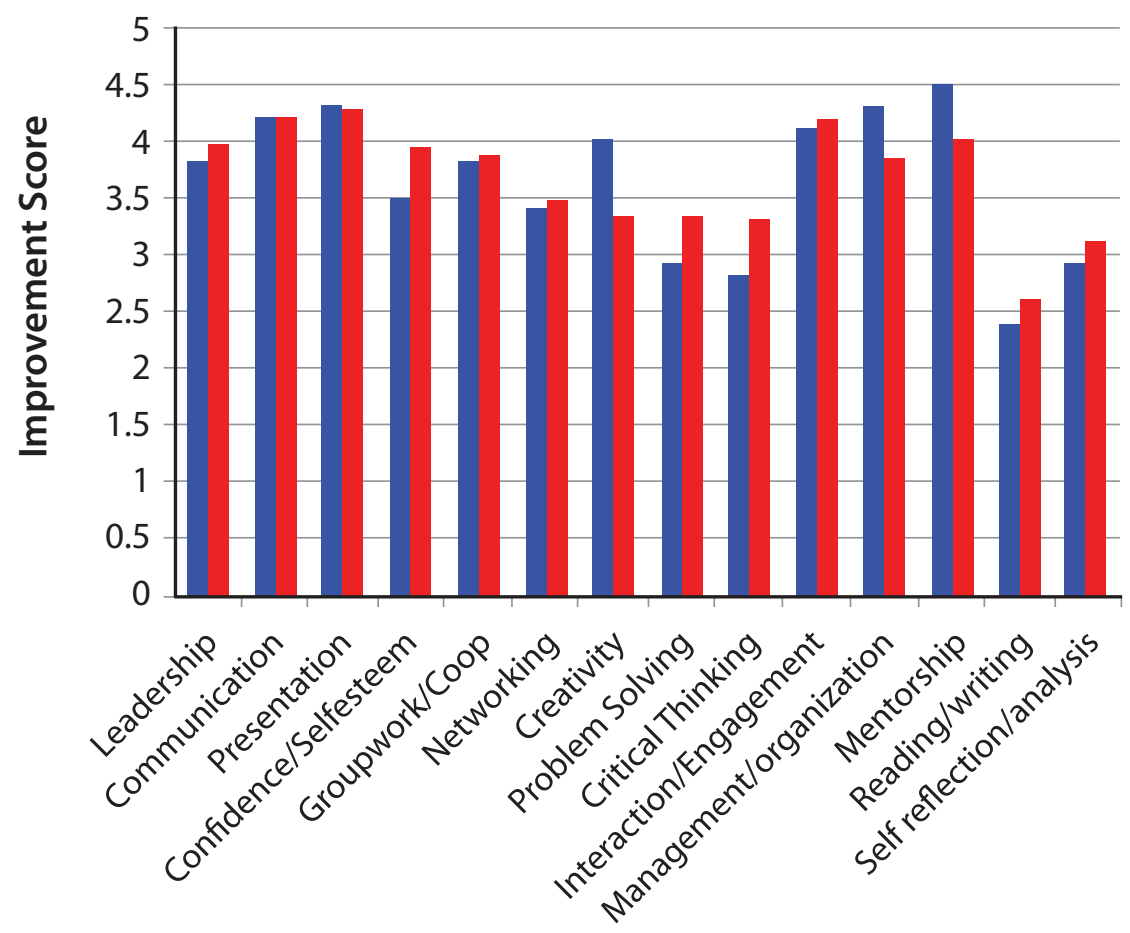

FIGURE 2B

Comparison of Skill

Enhancement Between Active and Non-Active (Alumni)

Volunteers in LTSPP

Skills 


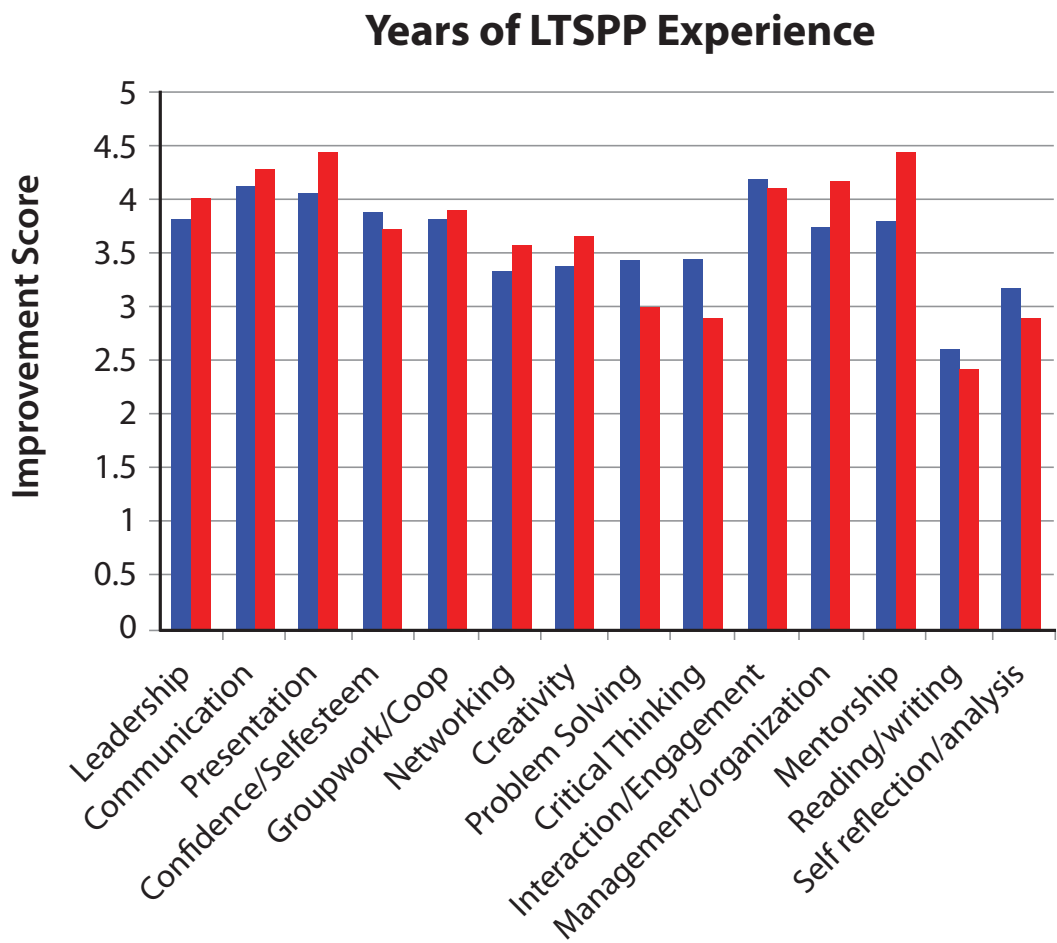

- Less than one year

One year or more

Figure 3A

Comparison of Skill

Enhancement Between

Experienced and Novice

LTSPP Volunteers

Skills

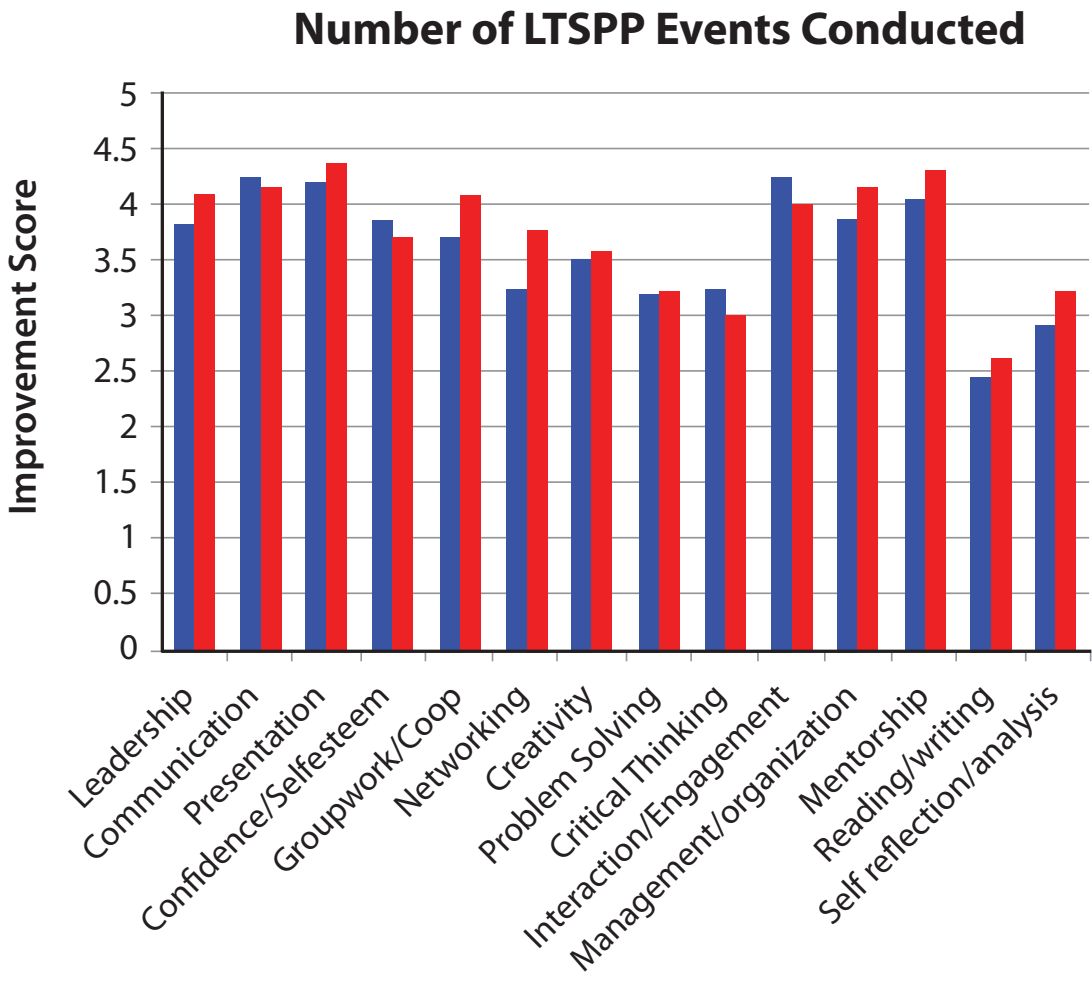

Less than 5

5 or more

Figure 3B

Comparison of Skill

Enhancement Based on Number of Events Conducted by LTSPP Volunteers

Skills 
skill category when comparing between volunteers that have done more or fewer activities (Figure 3B). When looking at the trend of the improvement scores, more experienced volunteers felt that LTSPP improved their presentation and mentorship skills, whereas more novice volunteers felt an improvement in communication and interaction skills (Figures 3A and 3B).

\section{Discussion and Conclusion}

Volunteers attributed improvements to several transferable skills to their involvement with LTSPP. The overwhelmingly positive remarks by respondents can be accredited to several possible reasons. LTSPP provides an opportunity to learn without risk of failing or competing for grades. In this process, volunteers are encouraged to learn varying activities and the science behind them. Through communicating with students at elementary and high school levels, volunteers are regarded as experts or knowledgeable in a given topic, and encourage volunteers to see themselves as being qualified, smart scientists. Additionally, volunteers communicated an appreciation for being affiliated with a national science organization and university. As a result, confidence and interest in science is supported through LTSPP.

Enhancement of the four main skills volunteers identified (i.e., communication, presentation, interaction and mentorship) can be potentially attributed to the nature and mode of delivery of the various science outreach activities and demonstrations. LTSPP activities tend to involve volunteers working together in pairs or groups who present in front of a group of students on a basic science topic. Successful delivery of the activity often requires active interaction and communication between the participating volunteers, with more experienced volunteers leading less experienced ones, as well as intensive preparation of how the material will be presented to the students. Consequently, the volunteers are frequently encountering and developing these four main skills in each activity they take part in. Reading and writing skills were found to be least enhanced since the bulk of the activities required only some basic science background knowledge to carry out, in particular for the lower grade levels. Since most of the participating volunteers tended to have some knowledge of basic science, there was not a huge necessity to neither extensively read up on the literature or take down lengthy notes from the literature review on the science topic they were presenting; although some brief review was generally required for mastery of the topic.

When comparing the specific groupings of volunteers, both undergraduate and graduate students thought to have improved on their presentation skills, but graduate students found mentorship skills also improved, compared to communication/interaction skills for undergraduates. Undergraduate education at large universities usually have large classes with multiple choice exams as the main mode of assessment in the lower years, while gradually moving to smaller classes with labs, assignments, and presentations in the upper years. In doing so, this has limited the opportunities for undergraduates to build on their communication and interaction skills until they are closer to their year of graduation. Hence, LTSPP provides an outlet that enables the undergraduates to improve on these skills. On the other hand, graduate students would have already undertaken the undergraduate curriculum and would then be seen more as the 'mentors,' as they would be able to provide guidance and the sharing of knowledge and skills with undergraduates. It is interesting to note that when comparing active volunteers with alumni, in which the bulk of the alumni were now currently employed in a career, creativity was significantly enhanced for alumni. This could be resulting from the numerous experiences they had encountered during their tenure as LTSPP volunteers, as well as the skills they developed through the program, that has now enabled them to intricately transfer those skills and experiences and apply them in their own workplace. Finally, when comparing novice and experienced volunteers, experienced volunteers mimicked the trend seen for graduate students and novice volunteers mimicked the trend seen for undergraduates in terms of skills enhancement. In particular, the significant difference in experienced volunteers having more enhanced mentorship skills compared to novice volunteers further strengthens 
the notion that volunteers that have been in the program longer or have a higher education level tend to take on the mentorship role to support and guide other volunteers in their outreach activities.

It is also interesting that in most cases, volunteers did not strongly associate problem solving and critical thinking skills with volunteering through LTSPP. Although these skills are often exercised throughout a given activity (e.g., time management, adapting activities for a specific class, trouble-shooting protocols, or equipment), it appears that volunteers felt that the communication and presentation skills were more important. Respondents also commented on how the program did not directly lead to career options but did improve their confidence and skill set when seeking new jobs either during university or upon graduating. All respondents felt that the LTSPP program was a superior program for science outreach and career skills and professional development.

The following are quotes from volunteers of the LTSPP program at UTSC that help exemplify the success of the science outreach program in enhancing their professional skills:

"It has allowed me to present material in a fun way with clarity and confidence, and reduce my level of anxiety when speaking in front of an audience." [third-year undergraduate student in Human Biology]

"It has enhanced my connection to my community." [fourth-year undergraduate student in Cell and Molecular Biology]

"It has made a huge difference in my life, as I obtained and enhanced many skills and developed a new passion for science and teaching." [fifth-year doctoral student in Biology]

"The program is very diverse and is a great way to gain communication skills." [first-year undergraduate student in Integrative Biology]
"I enjoyed working as a team with other teammates and improved my organizational skills." [first-year masters' student in Environmental Sciences]

Overall, LTSPP at UTSC was largely successful in improving the communication, presentation, mentorship, and interaction skills of volunteers, regardless of their program (i.e., graduate or undergraduate), their experience in the program, or their status (alumnus versus active). In particular, the enhancement of mentorship skills was shown to be significantly different between novice and experienced volunteers, with greater enhancement in experienced volunteers, and alumni of the LTSPP program believed their creativity skills were significantly enhanced. Confidence and interest in science as a discipline was also a positive benefit for volunteers. This study demonstrates how experiences in university that occur outside of the classroom are viewed as being beneficial to university students. Future work could address whether student experiences are enhanced due to these opportunities, if it improves their academic performance, and also whether administrators perceive this program as being beneficial to the university student experience.

\section{Acknowledgements}

Funding for this research was provided through the Let's Talk Science Partnership Program and the Office of the Vice Principal (Research) at University of Toronto Scarborough. We would like to thank the volunteers and coordinators of the Let's Talk Science Partnership Program at University of Toronto Scarborough, the Let's Talk Science National Office, and the educators for their time and efforts.

\section{References}

Dolan, D. (2009). Moving ahead. University of Toronto Scarborough Annual Review, 1-64. 
Let's Talk Science. (2010). Retrieved from http:// www.letstalkscience.ca

\section{Biographies}

Edward Eng and Catherine Febria are both former Let's Talk Science Partnership Program coordinators, Teaching Assistant Training Program trainers, as well as Ph.D. candidates in the Department of Biological Sciences at University of Toronto Scarborough. Edward is also a lecturer for a science engagement course at University of Toronto Scarborough. 


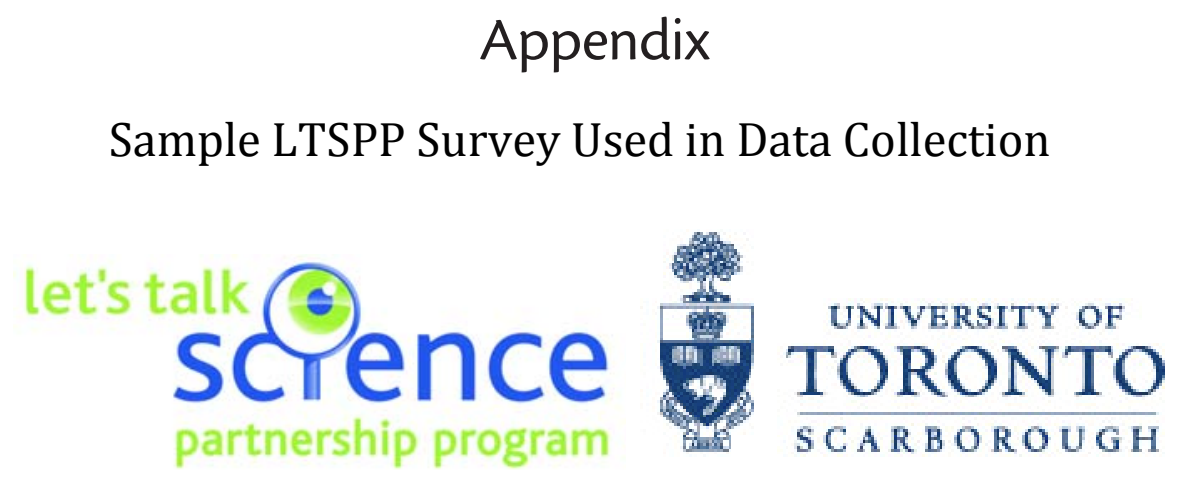

\section{Let's Talk Science Partnership Program: Post-Survey}

1. Current occupation and description of work (if applicable):

2. Program(s) of study and number of years at UTSC:

3. Volunteer experience in Let's Talk Science at UTSC: year(s) and month(s)

4. Approximately how many LTS events did you do per year? and approximately how many LTS events did you do in total?

5. Prior volunteer experience (not including LTS and current volunteer work).

6. Prior work experience (not including graduate school and current occupation)

7. What were your impressions of LTS before you started?

8. What are your impressions of LTS now after your participation in the program?

9. What key skills did you obtain or build through volunteering with LTS?

For the following skills/attributes listed, please indicate how much the LTS program had affected or enhanced you in.

1 - not at all, 2 - very little, 3 - somewhat, 4 - quite significantly, 5 - very significantly

Leadership

Communication

Presentation $\begin{array}{llllll}1 & 2 & 3 & 4 & 5 & \mathrm{n} / \mathrm{a}\end{array}$

$\begin{array}{llllll}1 & 2 & 3 & 4 & 5 & \mathrm{n} / \mathrm{a}\end{array}$

$\begin{array}{llllll}1 & 2 & 3 & 4 & 5 & \mathrm{n} / \mathrm{a}\end{array}$




$\begin{array}{lllllll}\text { Confidence/Self-esteem } & 1 & 2 & 3 & 4 & 5 & \text { n/a } \\ \text { Groupwork/Cooperation } & 1 & 2 & 3 & 4 & 5 & \text { n/a } \\ \text { Networking } & 1 & 2 & 3 & 4 & 5 & \text { n/a } \\ \text { Creativity } & 1 & 2 & 3 & 4 & 5 & \text { n/a } \\ \text { Problem Solving } & 1 & 2 & 3 & 4 & 5 & \text { n/a } \\ \text { Critical Thinking } & 1 & 2 & 3 & 4 & 5 & \text { n/a } \\ \text { Interaction/Engagement } & 1 & 2 & 3 & 4 & 5 & \text { n/a } \\ \text { Management/Organization } & 1 & 2 & 3 & 4 & 5 & \text { n/a } \\ \text { Mentorship } & 1 & 2 & 3 & 4 & 5 & \text { n/a } \\ \text { Reading/Writing } & 1 & 2 & 3 & 4 & 5 & \text { n/a } \\ \text { Self-Reflection/Analysis } & 1 & 2 & 3 & 4 & 5 & \text { n/a }\end{array}$

10. Did volunteering with LTS help or influence your current career/career goals or your long-term career plans? If so, how?

11. Do you still volunteer in general now? If so, please describe (If also still volunteering for LTS, please state).

12. Would you recommend LTS to others for career-building and professional development skills?

13. Additional comments.

I understand that the results of this survey will never be connected to my name, I AM willing to have them included in the data for a research study

Although I understand that the results of this survey will never be connected to my name, I do NOT wish to have them included in the data for a research study 